\title{
How do the success factors driving repurchase intent differ between male and female customers?
}

\author{
Björn Frank • Takao Enkawa • Shane J. Schvaneveldt
}

Received: 30 October 2012 / Accepted: 18 June 2013 / Published online: 16 July 2013

(C) The Author(s) 2013. This article is published with open access at Springerlink.com

\begin{abstract}
As customers' repurchase behavior leads to longterm corporate profitability, managers should know the success factors influencing repurchase intent. Knowledge of gender differences in these success factors would enable managers to separately optimize repurchase intent for men and women. This research thus develops original hypotheses on gender differences in the formation of repurchase intent. Based on hierarchical linear modeling of data from five countries and ten industries, this research finds that public brand image more strongly influences customer satisfaction and repurchase intent for women than for men. Perceived value has a weaker effect on repurchase intent for women than for men. The analyses do not detect any gender difference in the influence of customer satisfaction on repurchase intent. Contrary to conventional wisdom, relational switching costs more strongly influence repurchase intent for men than for women. Further analyses illustrate moderating effects of country differences in gender egalitarianism and of contextual differences between products and services.
\end{abstract}

Keywords Repurchase intent · Customer loyalty · Gender . Sex $\cdot$ Gender egalitarianism $\cdot$ Public brand image

\section{Introduction}

Marketing managers strive to achieve high levels of repurchase intent among their customers because repurchase intent is among the most important drivers of long-term financial

\footnotetext{
B. Frank $(\bowtie) \cdot$ T. Enkawa

Department of Industrial Engineering and Management, Tokyo Institute of Technology, W9-53, 2-12-1 O-okayama, Meguro-ku, Tokyo 152-8552, Japan

e-mail: frank.b.aa@m.titech.ac.jp

S. J. Schvaneveldt

Goddard School of Business and Economics, Weber State University, 3802 University Circle, Ogden, UT 84408-3802, USA
}

performance (Reichheld and Sasser 1990). Customers with high repurchase intent require much lower marketing expenses to complete a purchase than do regular customers (Fornell et al. 2005; Reichheld and Sasser 1990). Moreover, they tend to pay higher prices, buy higher quantities, and engage in positive word-of-mouth referrals that attract new customers (Ngobo 2004; Reichheld and Sasser 1990). In order to maximize customers' repurchase intentions, managers need to know the success factors influencing repurchase intent and their relative importance. Knowledge of gender-related differences in these success factors would be highly valuable because it is easy to address men and women as separate market segments (Putrevu 2001) and separately optimize male and female repurchase intentions with different strategies. Although psychological research has illuminated general differences between men and women, it is not yet clear how these differences translate to the formation of repurchase intent.

The marketing literature, which often treats repurchase intent as part of multi-item (often multi-dimensional) customer loyalty constructs, so far has neglected this managerially important topic. Early studies argued that men are more loyal than women to firms (Melnyk et al. 2009, Studies 4-5) and that customer satisfaction is a more important driver of repurchase intent for men than for women (Mittal and Kamakura 2001). Beyond these studies, the literature lacks a theory of how gender moderates the formation of repurchase intent. Due to the practical importance of gender-specific marketing (Putrevu 2001), this lack of research highlights a need for theory development to provide managers with knowledge of gender differences in the success factors driving repurchase intent. The creation and validation of such theories would thus strongly contribute to marketing theory and practice.

Drawing on the gender psychology literature, we will develop original hypotheses about the moderating effects of gender on the formation of repurchase intent. Figure 1 illustrates our research framework and hypotheses, and Fig. 2 provides a structured overview of the argumentation and literature used for developing our core hypotheses. These core 
Fig. 1 Conceptual framework and research hypotheses: the formation of repurchase intent

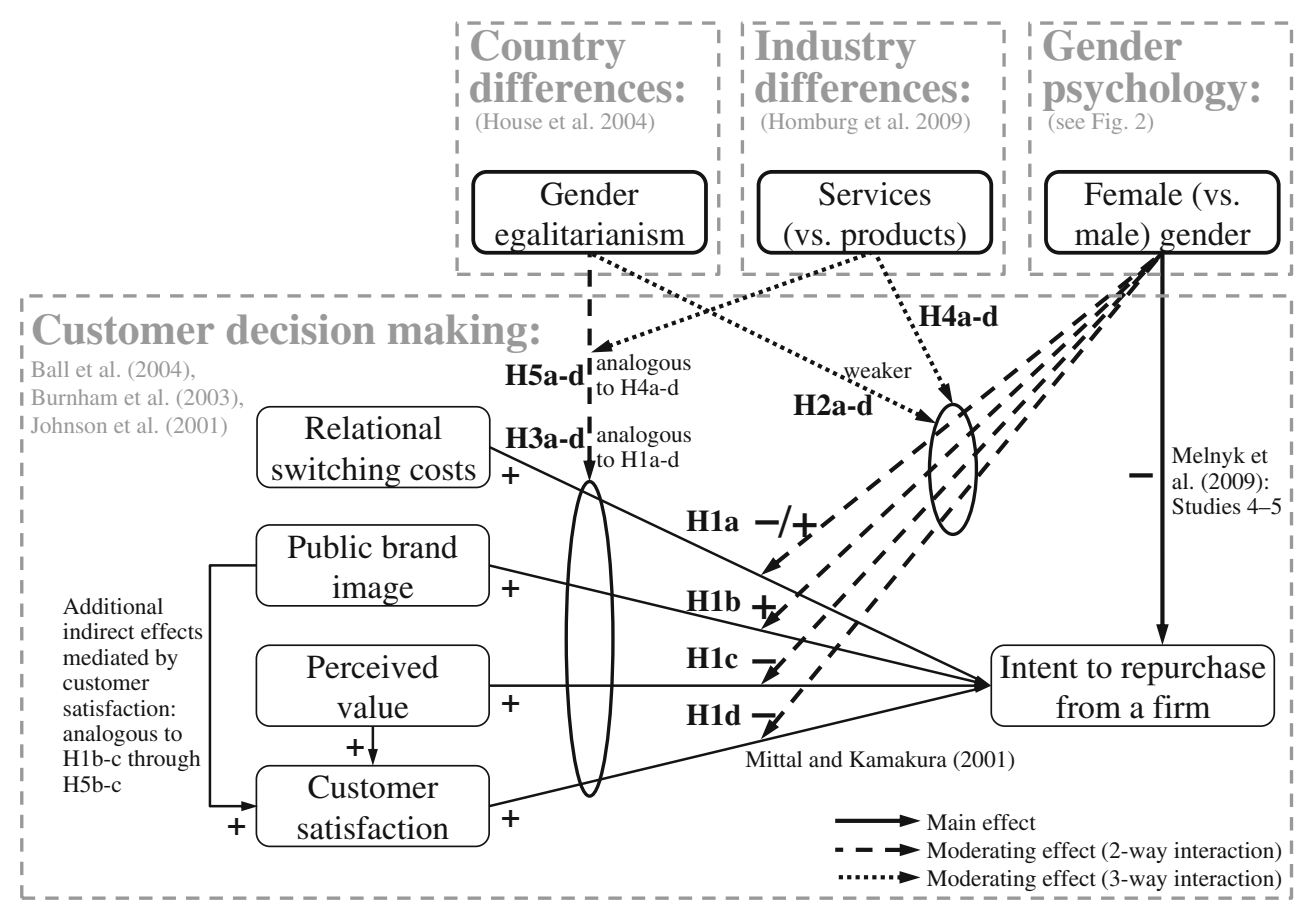

hypotheses will suggest that public brand image (H1b) has a stronger effect, and perceived value (H1c) and customer satisfaction (H1d) have weaker effects, on repurchase intent for women than men. Furthermore, different mechanisms found by the gender literature provide grounds for opposing hypotheses on whether relational switching costs have weaker (H1a) or stronger (H1a [alt]) effects on repurchase intent for women than men. Additional hypotheses will focus on moderating effects of country differences in gender egalitarianism $(\mathrm{H} 2 \mathrm{a}$ to $\mathrm{H} 3 \mathrm{~d}$ ) and of contextual differences between products and services (H4a to $\mathrm{H} 5 \mathrm{~d}$ ).

Using hierarchical linear modeling, our study will empirically test these hypotheses with a dataset from five countries (Bolivia, China, Japan, Thailand, U.S.) and ten industries including four products (automobiles, mobile phones, personal computers, shampoo) and six services (banks, fast food restaurants, hairdressers, hospitals, mobile carriers, supermarkets). For contextual completeness, we will also attempt to verify the conclusions of past research showing that men have higher intentions than women to repurchase from firms (Melnyk et al. 2009, Studies 4-5).

\section{Background knowledge}

Provider-related customer attitudes affecting repurchase intent

Provider-related customer attitudes relate to the primary firm providing goods and services to the customer in an industry (Fornell et al. 2005). Knowledge of gender differences in the effects of such customer attitudes on repurchase intent would help managers optimize widely used gender-specific marketing strategies (Putrevu 2001) to maximize repurchase intent. Before developing hypotheses on these gender differences, we will draw on established national customer satisfaction index models and more recent studies (Ball et al. 2004; Burnham et al. 2003; Fornell et al. 2005; Johnson et al. 2001) to review the provider-related customer attitudes exerting the strongest direct effects on repurchase intent. For reasons of parsimony, our conceptual model in Fig. 1 centers on these relationships and omits variables whose effects on repurchase intent are purely mediated by variables already included in the model (e.g., perceived quality: Fornell et al. 2005; Johnson et al. 2001; Türkyılmaz and Özkan 2007).

In the literature, customer satisfaction with products and services is the most widely accepted determinant of repurchase intent. Satisfied customers repurchase to sustain their satisfaction, whereas dissatisfied customers switch providers to find higher satisfaction elsewhere (Johnson et al. 2001). The perceived value of goods and services is defined as perceived quality compared to the price (Fornell et al. 2005). As perceived value influences customer satisfaction, its effect on repurchase intent is mediated by customer satisfaction (Fornell et al. 2005). Due to the importance of price in repurchase decisions, perceived value also affects repurchase intent directly (Johnson et al. 2001; Ngobo 2004).

Another key determinant of repurchase intent is public brand image, which the literature also tends to call corporate image in cases where brand names are identical with company names (Johnson et al. 2001). Public brand image is the perceived overall public opinion of a brand (Johnson et al. 2001). It differs from most definitions of brand image in two ways. First, public 
Gender Literature:

General Psychological

Gender Differences

(stated for women

compared with men)
Consequences:

Gender Differences in the

Importance of Antecedents to Repurchase Intent

(stated for women compared with $\underline{\text { men) }}$
(Baumeister and Sommer 1997; Melnyk et al. 2009)
(1996; Cron et al. 2009; Iacobucci and Ostrom 1993),
more interdependent self-construal (Cross and Madson
(Baumeister and Sommer 1997; Melnyk et al. 2009),
and higher sensitivity to interpersonal cues (Rubin and
Brown 1975; Stuhlmacher and Walters 1999)
(n) consumption decisions, higher importance of
(1993; Mittal and Kamakura 2001; Noble et al. 2006;
Otnes and McGrath 2001), personal recommendations
commitment (Shemwell and Cronin 1995)

- Higher importance of trust (Ndubisi 2006; Shemwell and Cronin 1995), risk reduction (Garbarino and Strahilevitz 2004), and security (Schwartz and RubelLifschitz 2005, 2009)

- Greater fear of negative evaluations in social settings (Carleton et al. 2007; Habke et al. 1997), higher sensitivity to interpersonal cues (Rubin and Brown 1975; Stuhlmacher and Walters 1999), higher importance of security (Schwartz and Rubel-Lifschitz 2005, 2009), and higher importance of impressing others (Lawrence et al. 2006; Moutinho et al. 1996)

- Stronger attraction by exclusivity and uniqueness o products (Noble et al. 2006)

- Greater relationship orientation (Cataldi and Reardon 1996; Cron et al. 2009; Iacobucci and Ostrom 1993) and more relationally interdependent self-construal (Baumeister and Sommer 1997; Melnyk et al. 2009)

- Greater openness to persuasion (Eagly and Carli 1981; Meyers-Levy 1988; Rubin and Brown 1975;

Stuhlmacher and Walters 1999)

- Stronger interpretation of price as an indicator of quality (Moutinho et al. 1996)

- Lower task orientation (Meyers-Levy 1988) and lower emphasis on efficiency and achievement (Eagly 1987; Schwartz and Rubel-Lifschitz 2005, 2009), also in shopping (Noble et al. 2006; Otnes and McGrath 2001)$$
\text { (1) }
$$

- Less instrumental vs. expressive orientation (Zelditch

1955) and lower emphasis on achievement (Eagly

1987; Schwartz and Rubel-Lifschitz 2005, 2009; Otnes and McGrath 2001) _ _ _ _ _ _ _ _ I

1

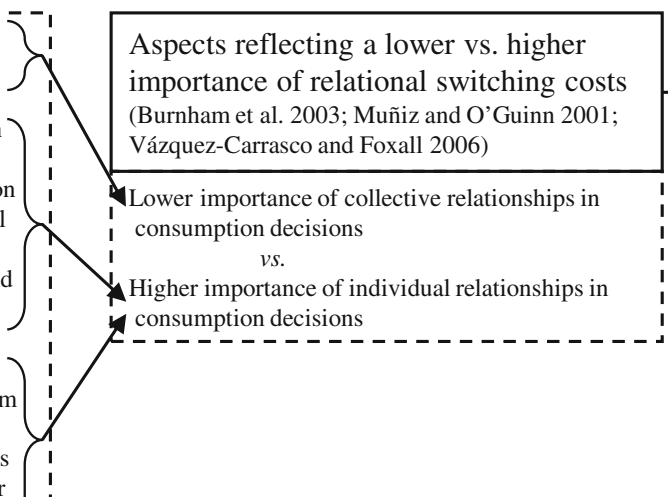

Aspects reflecting a higher importance of public brand image (Ball et al. 2004; Fischer et al. 2010; Türkyılmaz and Özkan 2007)

Higher importance of signals of trust and safety

Higher importance of social demonstrance through

image transfers from brands

Aspects reflecting a lower importance of perceived value (= quality / price) (Johnson et al. 2001; Ngobo 2004)

Willingness to pay price premium for further needs associated with the importance of public brand

image, exclusivity, and uniqueness (Fischer et al. 2010; Tian et al. 2001)

Willingness to pay more to maintain personal relationships (Cron et al. 2009; Gelfand et al. 2006)

Acceptance of higher prices due to higher persuasiveness of advertising and salespeople

Greater tendency to mistrust low-priced products $\int \frac{1}{1}$

More compromises on quality (Chiu 2002;

Iacobucci and Ostrom 1993) and price (Gelfand et al. 2006; Stuhlmacher and Walters 1999)

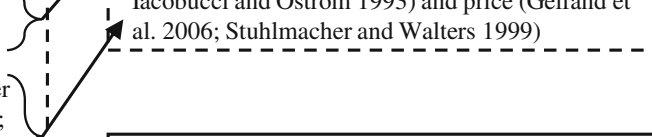

Aspects reflecting a lower importance of customer satisfaction with products and services (Johnson et al. 2001)

Less emphasis on obtaining the most satisfying core offerings (i.e., products and services) as opposed to I peripheral aspects of the shopping experience (Campbell 1997; Otnes and McGrath 2001)
Integrated Theories: Summary of Hypotheses

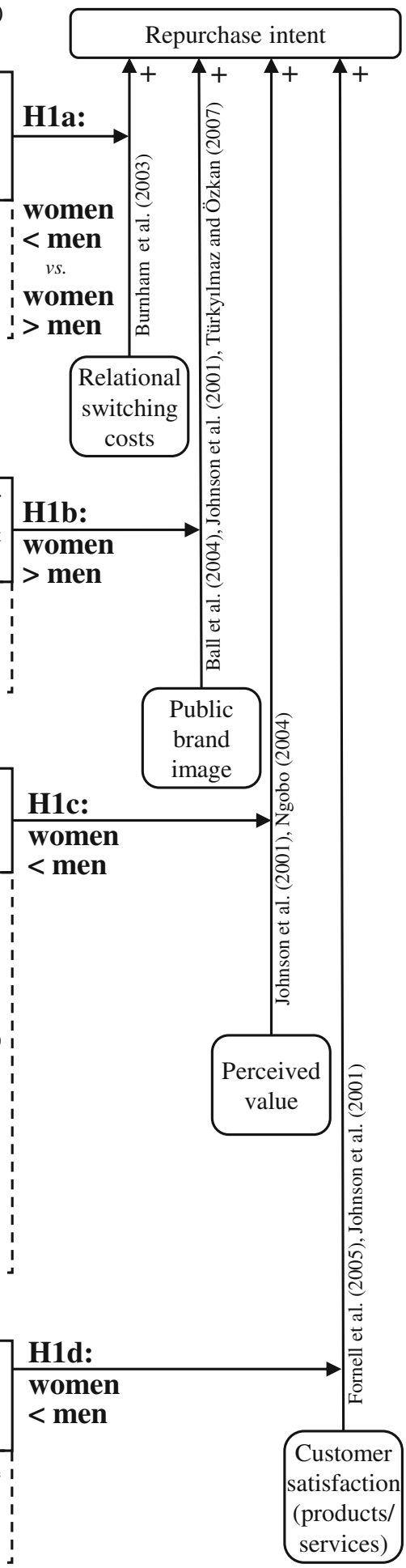

Fig. 2 Integration of the gender literature into the development of hypotheses 
brand image is not a purely personal perception of brand image but an assessment of the average public perception of brand image. Second, while the literature tends to conceptualize brand image as a multi-dimensional characterization of a brand, consumers aggregate their information in a subjectively weighted manner and make an overall evaluation of goodness vs. badness to simplify decision making (Aaker 1991; Ball et al. 2004; Türky1lmaz and Özkan 2007). As our article deals with decision making, we will adopt this definition of public brand image as the perceived public overall evaluation (good vs. bad) of a brand (Johnson et al. 2001). Its effects on repurchase intent have been demonstrated in various countries and industries with large-scale data from national customer barometers (Ball et al. 2004, 2006; Johnson et al. 2001; Türky1lmaz and Özkan 2007). Public brand image has been shown to influence repurchase intent directly (Johnson et al. 2001) and indirectly through customer satisfaction (Ball et al. 2004, 2006; Türky1lmaz and Özkan 2007). By trusting opinions prevalent in the social environment, customers can infer a provider's average performance (Ball et al. 2004; Fischer et al. 2010). Moreover, they can make sure to select products and services that meet the tastes of their social environment and contribute to positive social relationships (Ball et al. 2004; Escalas and Bettman 2005; Türkyılmaz and Özkan 2007).

Switching costs are barriers impeding the change from the incumbent to another provider of goods and services (Burnham et al. 2003). While various switching cost types exist, research has shown that relational switching costs have, by far, the strongest impact on repurchase intent (Burnham et al. 2003; Vázquez-Carrasco and Foxall 2006). This effect means that customers stay with providers as they fear to harm relationships with salespeople, friends, and the brand community (Muñiz and O'Guinn 2001).

Gender differences in the formation of repurchase intent: existing theories

Despite a plenitude of research on psychological differences between men and women, it is virtually unknown how these general gender differences translate to the formation of repurchase intent. To our knowledge, merely a single study has tested a moderating effect of gender on the formation of repurchase intent. In a single industry and without any specific theory building, Mittal and Kamakura (2001) found a stronger effect of customer satisfaction on male than on female repurchase behavior. Despite an extensive search, we are not aware of any research on gender differences in the effects of the other antecedents on repurchase intent, such as public brand image, perceived value, and relational switching costs. Our study thus seeks to address this lack of research and generate knowledge of this managerially important topic.

Another study developed theory on a main effect of gender on customer loyalty. Melnyk et al. (2009, Studies 4-5) found that men are more loyal to firms than are women. They argued that men are more collectively interdependent and associate firms and their offerings with collective entities. This theory contradicts marketing studies that include gender as a control variable. Such studies found the level of repurchase intent to be higher for women than for men (Dimitriades 2006; Mittal and Kamakura 2001) or to not differ significantly by gender (Bell et al. 2005; Bendall-Lyon and Powers 2002; Kim and Yoon 2004; McGoldrick and Andre 1997). Thus, there may be a need for further verification.

While our analysis will attempt to empirically verify the effects predicted by Melnyk et al. (2009) as well as Mittal and Kamakura (2001), our theory development will focus on original hypotheses that complement these existing theories and contribute new insights to the literature.

\section{Development of hypotheses}

Moderating effects of gender on the formation of repurchase intent

From established findings of general psychological differences between men and women, we will derive gender differences in aspects that the marketing literature associates with the importance (i.e., influential strength) of relational switching costs (H1a), public brand image (H1b), perceived value (H1c), and customer satisfaction (H1d). These are among the principal drivers of repurchase intent (Burnham et al. 2003; Johnson et al. 2001). Therefore, gender differences in such aspects would define potential moderating effects of gender on the formation of repurchase intent (see Fig. 2).

Customers can form personal relationships with sales staff or other firm personnel, with friends using products and services of the same firm, and with members of the brand community (Burnham et al. 2003; Muñiz and O'Guinn 2001). Switching providers may hurt these relationships by offending staff, loosening bonds with friends, and reducing common points of identification (Burnham et al. 2003). As humans have a fundamental need to belong (Baumeister and Leary 1995), customers dislike hurting relationships by switching providers. These relationships thus constitute relational switching costs (Burnham et al. 2003; Vázquez-Carrasco and Foxall 2006).

Based on the gender literature, we will predict gender differences in the influence of relational switching costs on repurchase intent (see Fig. 2). Intriguingly, modern and traditional gender theories lead to distinct predictions which we will compare and test against each other. Drawing on the modern gender theory proposed by Baumeister and Sommer (1997), Melnyk et al. (2009) found that men have a more collectively interdependent self-construal, whereas women have a more relationally interdependent self-construal. That is, men focus on maintaining relationships with abstract and large groupings 
of people, whereas women focus on maintaining relationships with specific individuals. This theory would suggest that men will react more strongly to relational switching costs arising from collective relationships constituted by the totality of individual personal relationships and by more anonymous relationships with staff and other users (H1a), whereas women will react more strongly to relational switching costs arising from individual relationships with company staff or other users (H1a [alt]). The predominant nature of relationships in industry-specific contexts thus might influence the overall outcome of these opposing effects (see H4a).

By contrast, studies drawing on traditional gender theory emphasize that men have a more independent self-construal, whereas women have a more interdependent self-construal (Cross and Madson 1997). Such studies report that women are more relationship-oriented (Cataldi and Reardon 1996; Cron et al. 2009; Iacobucci and Ostrom 1993), more interdependent in general (Cross and Madson 1997), and more sensitive to interpersonal cues than are men (Rubin and Brown 1975; Stuhlmacher and Walters 1999). Moreover, they report that relational elements such as personal interaction (Chiu 2002; Iacobucci and Ostrom 1993; Noble et al. 2006; Otnes and McGrath 2001), personal recommendations (Garbarino and Strahilevitz 2004), and service worker commitment (Shemwell and Cronin 1995) are more important in consumption for women than for men. Without distinguishing between individual and collective relationships, these studies suggest that women generally accord greater importance than do men to relationships in consumption decisions and, hence, generally react more strongly to relational switching costs in repurchase decisions (H1a [alt]).

H1a: The positive effect of relational switching costs on repurchase intent is weaker for women than for men. H1a [alt]: The positive effect of relational switching costs on repurchase intent is stronger for women than for men.

A good public brand image conveys trust in product choices and allows for social demonstrance, that is, impressing other consumers (Ball et al. 2004; Fischer et al. 2010; Türkyılmaz and Özkan 2007). A gender difference in the effect of public brand image on repurchase intent (H1b) thus would originate from gender differences in the importance of these two functions of public brand image.

Specifically, public brand image reflects public trust in a brand, reduces perceived risk, and is sensitive to product safety concerns (Ball et al. 2004; Fischer et al. 2010). The literature shows that women attach greater importance than do men to trust (Ndubisi 2006; Shemwell and Cronin 1995), to risk reduction (Garbarino and Strahilevitz 2004), and to security (Schwartz and Rubel-Lifschitz 2005, 2009). Hence, we posit that public brand image more strongly affects female than male repurchase intent.

Moreover, the gender literature reports that women have greater fear of negative evaluations in social settings (Carleton et al. 2007; Habke et al. 1997), higher sensitivity to interpersonal cues (Rubin and Brown 1975; Stuhlmacher and Walters 1999), and a stronger appreciation of security than do men (Schwartz and Rubel-Lifschitz 2005, 2009). Thus, women's social confidence depends more strongly on their self-image and on how they impress others (Lawrence et al. 2006; Moutinho et al. 1996). Consistent consumption of the same brand with a good public image enables consumers to transfer positive public brand associations to the self (Aaker 1991; Ball et al. 2004; Escalas and Bettman 2005; Türkyılmaz and Özkan 2007). Consequently, we posit that women emphasize such image transfers more than men to avoid negative interpersonal cues and evaluations, feel safe in social settings, and gain social confidence by impressing others. Likewise, this mechanism would imply a greater importance of public brand image to women than men.

$\mathrm{H} 1 \mathrm{~b}$ : The positive effect of public brand image on repurchase intent is stronger for women than for men.

The perceived value of goods and services is defined as perceived quality compared with the price (Fornell et al. 2005). Higher perceived value is attained by either higher perceived quality for the same price or the same perceived quality for a lower price. Gender differences in how perceived value affects repurchase intent $(\mathrm{H} 1 \mathrm{c})$ are thus caused by gender differences in the importance of quality or price.

In developing $\mathrm{H} 1 \mathrm{~b}$, we posited that women's particular psychological and social needs lead to a greater impact of public brand image on repurchase intent for women than men. As public brand image positively affects willingness to pay (Fischer et al. 2010), women may be willing to pay a price premium to satisfy these particular needs through consumption.

Similarly, the literature indicates that women are attracted by exclusivity and uniqueness as attributes of products and services (Noble et al. 2006). Since need for uniqueness positively affects willingness to pay (Tian et al. 2001), women may be ready to pay higher prices to obtain these attributes.

Additionally, the gender literature reports that women focus more than men do on maintaining relationships (Cataldi and Reardon 1996; Cron et al. 2009; Cross and Madson 1997; Iacobucci and Ostrom 1993) or at least individual (as opposed to collective) relationships (Baumeister and Sommer 1997; Melnyk et al. 2009). In this context, women have been shown to pay more than men in order to maintain harmonious relationships with salespeople and obtain products which are certain to please other people and thus contribute to recognition in relationships (Cron et al. 2009; Gelfand et al. 2006).

Moreover, the gender literature reports greater openness to persuasion for women than for men (Eagly and Carli 1981; Meyers-Levy 1988; Rubin and Brown 1975; Stuhlmacher and Walters 1999). This may suggest that advertising and salespeople can more easily convince women of paying higher prices. Research has also shown that women more strongly interpret price as an indicator of quality (Moutinho et al. 
1996). Hence, women tend more to mistrust and avoid very low-priced products.

Further research has shown that men are more taskoriented and emphasize efficiency and achievement more than women do (Eagly 1987; Meyers-Levy 1988; Schwartz and Rubel-Lifschitz 2005, 2009). This difference also holds in shopping behavior (Noble et al. 2006; Otnes and McGrath 2001). Compared with women, men thus make fewer compromises on low price (Gelfand et al. 2006; Stuhlmacher and Walters 1999) and high product quality (Chiu 2002; Iacobucci and Ostrom 1993).

In summary, psychological evidence of gender differences provides grounds to presume that men focus more than women on high quality and low price in repurchase decisions. Hence, we posit that perceived value (quality over price) has a weaker effect on female than male repurchase intentions.

H1c: The positive effect of perceived value on repurchase intent is weaker for women than for men.

Without any specific theory building, Mittal and Kamakura (2001) empirically found a stronger effect of customer satisfaction on male than female repurchase behavior in the U.S. automotive industry. We propose a mechanism explaining this gender difference. According to gender schemata theory, which was confirmed across cultures, men are raised to fulfill more instrumental roles, whereas women are raised to fulfill more expressive roles (Zelditch 1955). Based on this conceptual foundation, Campbell (1997) argued that men view shopping as a needs-driven process and focus on the product or service, whereas women view shopping as a recreational experience with social and hedonic benefits beyond the satisfaction arising from the product or service itself. Similarly, Otnes and McGrath (2001) suggested that stronger achievement orientation (Eagly 1987; confirmed by Schwartz and Rubel-Lifschitz 2005, 2009) leads men to focus more on obtaining the most satisfying products and services, whereas women take more account of peripheral aspects of the shopping experience. When forming repurchase intentions, men may thus rely more on customer satisfaction with products and services, while women may rely more on other benefits of the shopping experience.

H1d: The positive effect of customer satisfaction with products and services on repurchase intent is weaker for women than for men.

Moderating effects of country differences in gender egalitarianism

Gender differences in behavior have innate origins and rolespecific, cultural origins (Eagly 1987). H1a-d derive from cross-nationally validated results in the gender psychology literature and thus point to innate origins. However, these effects may interact with culture-specific gender roles and differ by country in strength. To learn more about the influence of culture-specific gender roles, we will examine the effects of country differences in gender egalitarianism, which is a cultural tendency to minimize gender role differences (House et al. 2004). It has been argued that pronounced cultural gender roles reinforce innate gender differences as boys and girls are educated to behave differently to fulfill their respective gender roles (House et al. 2004). Thus, we predict that our hypothesized gender differences (H1a-d) are weaker in cultures with stronger gender egalitarianism. Lack of support would suggest a purely innate rather than partially role-specific nature of our predicted gender differences.

$\mathrm{H} 2$ : Gender differences in the effects of (a) relational switching costs, (b) public brand image, (c) perceived value, and (d) customer satisfaction on repurchase intent are weaker in national cultures with stronger gender egalitarianism.

Interestingly, various cultural frameworks have shown that gender egalitarianism not only refers to the degree of gender role differences but also conveys whether innate male or innate female values are regarded as more desirable values for the society as a whole (Hofstede and Hofstede 2005; House et al. 2004). Cultures with high (low) gender egalitarianism tend to regard innate female (male) values as more desirable for all of their members (House et al. 2004). Since culture influences consumer preference structures (Soares et al. 2007), average consumers in cultures with strong (weak) gender egalitarianism may thus also tend to view consumer preference structures resulting from innate female (male) values as more desirable. Hence, we predict that strong vs. weak gender egalitarianism (H3a-d) exerts the same moderating effects on the formation of repurchase intent as female vs. male gender (H1a-d).

H3: The effects of (a) relational switching costs, (b) public brand image, (c) perceived value, and (d) customer satisfaction on repurchase intent differ between countries with strong and weak gender egalitarianism in the same way as predicted for differences between female and male customers (H1a-d).

Variation in the moderating effects of gender and gender egalitarianism across industries

H1a-d deal with how gender moderates the formation of repurchase intent, on average. However, these moderating effects may differ by industry if the relevance of the underlying processes (see middle column of Fig. 2) varies by industry context. A key characteristic of services, as opposed to products, is the inseparability of production and consumption (Homburg et al. 2009). Compared with products, services thus tend to provide customers with more and deeper individual relational interactions with the firm's staff, 
facilities, and other customers (Homburg et al. 2009). Many of our arguments for moderating effects of gender (H1a-c) involve gender differences in the importance of such relational aspects (see Fig. 2, middle column): importance of individual relationships in consumption decisions (H1a [alt]), importance of social demonstrance through positive image transfers from brands (H1b), willingness to pay more to maintain individual personal relationships, and acceptance of higher prices due to higher persuasiveness of salespeople (H1c). We thus posit that these hypothesized effects (H1a [alt], H1b-c) are more pronounced for services than for products. However, H1a rests upon the importance of collective relationships with more abstract and larger groupings of people. These relationships do not require the same degree of personal interaction and physical presence as individual relationships and are more shallow (Melnyk et al. 2009). Thus, we do not presume that H1a is stronger for services than products. As the overall gender difference in the effect of relational switching costs on repurchase intent depends on which of the opposing effects predicted by H1a and H1a [alt] prevails in a specific context, it should be shifted more in the direction of H1a [alt] in the case of services but not products.

The inseparability of the production and consumption of services further implies that the consumption of the core offering and the entire shopping experience tend to be intertwined processes in service industries but separate processes in product industries (Homburg et al. 2009). Our prediction of a gender difference in the effect of customer satisfaction with products and services (H1d) derives from the difference between a stronger emphasis on the core offering for men and a stronger emphasis on the shopping experience for women (Campbell 1997). As this difference in focus thus seems to be smaller for services than products, we posit that the hypothesized gender difference in the effect of customer satisfaction with products and services on repurchase intent (H1d) is smaller for services than products.

Services are also less tangible than products and thus tend to involve higher perceived purchase risk (Homburg et al. 2009). One of our arguments for a greater importance of public brand image to women than men $(\mathrm{H} 1 \mathrm{~b})$ focuses on greater female risk aversion and the role of public brand image in signaling public trust and low purchase risk. As higher perceived purchase risk in service industries amplifies the behavioral consequences of risk aversion (Homburg et al. 2009), we conclude again that gender differences in the importance of public brand image may be larger for services than products.

H4: Female (vs. male) gender more positively moderates the effects of (a) relational switching costs, (b) public brand image, and (d) customer satisfaction and more negatively moderates the effect of (c) perceived value on repurchase intent in the case of services as compared with products.
H3a-d predict that the formation of repurchase intent differs between countries with strong and weak gender egalitarianism in the same way as between female and male customers (H1a-d). As both sets of moderating effects derive from the same underlying mechanisms, we posit that these sets of moderating effects also exhibit analogous differences between products and services.

H5: Gender egalitarianism more positively moderates the effects of (a) relational switching costs, (b) public brand image, and (d) customer satisfaction and more negatively moderates the effect of (c) perceived value on repurchase intent in the case of services as compared with products.

Public brand image and perceived value influence repurchase intent directly (Johnson et al. 2001; Ngobo 2004) and indirectly through customer satisfaction (Ball et al. 2004, 2006; Fornell et al. 2005; Türkyılmaz and Özkan 2007). Our hypotheses derive from general psychological gender differences which cause gender differences in consumer preference structures. As these preference structures are activated not only when consumers decide on what to repurchase but also when they ponder what satisfies them (Fornell et al. 2005; Johnson et al. 2001), our hypotheses may apply to the formation of not only repurchase intent but also customer satisfaction. All hypothesized mechanisms involving the effects of public brand image and perceived value on repurchase intent may thus occur not only in their direct effects but also in their indirect effects mediated by customer satisfaction (see Fig. 1).

\section{Methodology}

To test our hypotheses (see Fig. 1), we designed a questionnaire including questions on age (control variable), gender (object of $\mathrm{H} 1-\mathrm{H} 2$ and $\mathrm{H} 4)$, repurchase intent (H1-H5), and providerrelated customer attitudes affecting repurchase intent (Burnham et al. 2003; Johnson et al. 2001): relational switching costs (H1H5: a), public brand image (H1-H5: b), perceived value (H1-H5: c), and customer satisfaction (H1-H5: d). Respondents were asked to indicate provider-related attitudes on 10-point Likerttype scales regarding their primarily used brand in an industry (as in the American and European Customer Satisfaction Index methodologies: Fornell et al. 2005; Johnson et al. 2001). To test our hypotheses about the effects of country differences in gender egalitarianism (H2-H3, H5), we targeted our questionnaire at an economically, culturally, and geographically diverse set of countries with broad differences in gender egalitarianism: Bolivia (Western, developing), China (Eastern, developing), Japan (Eastern, developed), Thailand (Eastern, developing), and the U.S. (Western, developed). According to GLOBE scores of gender egalitarianism practice (House et al. 2004), which our analyses will treat as a continuous country-level variable, gender 
Table 1 Sample distribution by country and industry

\begin{tabular}{|c|c|c|c|c|c|c|c|}
\hline Category & Industry & Bolivia & China & Japan & Thailand & U.S. & Total \\
\hline \multirow[t]{4}{*}{ Products } & Automobile & 225 & 130 & 808 & 156 & 338 & 1,657 \\
\hline & Mobile phone & 743 & 918 & 1,231 & 318 & 315 & 3,525 \\
\hline & Personal computer & 541 & 686 & 1,183 & 286 & 314 & 3,010 \\
\hline & Shampoo & 771 & 977 & 1,219 & 317 & 325 & 3,609 \\
\hline \multirow[t]{6}{*}{ Services } & Bank & 281 & 953 & 1,235 & 313 & 336 & 3,118 \\
\hline & Fast food restaurant & 479 & 674 & 871 & 249 & 336 & 2,609 \\
\hline & Hairdresser & 650 & 947 & 1,199 & 289 & 258 & 3,343 \\
\hline & Hospital & 454 & 829 & 1,107 & 286 & 316 & 2,992 \\
\hline & Mobile carrier & 745 & 880 & 1,244 & 320 & 325 & 3,514 \\
\hline & Supermarket & 354 & 936 & 1,217 & 284 & 332 & 3,123 \\
\hline Total & & 5,243 & 7,930 & 11,314 & 2,818 & 3,195 & 30,500 \\
\hline
\end{tabular}

egalitarianism is relatively low in China and Japan, medium in Thailand, and high in the U.S. and Bolivia (House et al. 2004).

To test our hypotheses on industry differences (H4-H5), we targeted our questionnaire at ten diverse industries existing in all survey countries: cars, cell phones, personal computers, shampoo (products), banks, fast food restaurants, hairdressers, hospitals, mobile carriers, and supermarkets (services).

Bergkvist and Rossiter (2007) showed that constructs with concrete singular objects and concrete attributes ought to be measured with single-item scales. As examples of such constructs, they cited perceived quality and overall brand attitude. Since our questionnaire was to elicit responses on concrete singular objects (consumers' primarily used brand) and measure constructs falling into Bergkvist and Rossiter's (2007) definition of concrete attributes, we used single-item scales. We used 10-point scales to discriminate sufficiently between single-item response categories (Bergkvist and Rossiter 2007).

The questions were tailored to fit every industry. Respondents were asked to skip industries in the case of no recent experience. For the example of shampoo, they were given the following questions: "How likely are you to buy your next shampoo from the same brand?" (repurchase intent; anchors: extremely unlikely/likely); "What is your overall satisfaction with this shampoo?" (customer satisfaction; extremely dissatisfied/satisfied); "How is the quality of your shampoo in relation to the price you initially paid for it?" (perceived value; extremely low/high); "What is your perception of the overall public image of this brand?" (public brand image; extremely bad/good); "I am afraid to lose personal relationships (with friends, staff, other users, brand community) by switching to another brand" (relational switching costs; absolutely disagree/agree). These questions were obtained from Fornell et al. (2005) (perceived value, repurchase intent), Johnson et al. (2001) (customer satisfaction, public brand image), and Burnham et al. (2003) (relational switching costs). Slight adaptations ensured crosslinguistic conformity. Independent multilingual teams translated the questionnaire from English into Spanish, Chinese, Uyghur (spoken in Northwest China), Japanese, and Thai and back for verification. We held group discussions to assure identical meanings across languages, pre-tested and discussed the questionnaires with independent native consumers, and repeatedly revised the questionnaires.

We collected data from Tokyo, Nagoya, and Toyama in Japan; Beijing, Shanghai, Wuhan, and Ürümqi in China; Chiang Mai in Thailand; Cochabamba, Santa Cruz, and La

Table 2 Pooled sample: descriptive statistics and correlations for men and women

\begin{tabular}{|c|c|c|c|c|c|c|c|c|c|}
\hline \multicolumn{2}{|c|}{ Variable } & \multirow{2}{*}{$\begin{array}{l}\text { Men } \\
\text { Mean (SD) }\end{array}$} & \multirow{2}{*}{$\begin{array}{l}\text { Women } \\
\text { Mean (SD) }\end{array}$} & \multirow{2}{*}{$\begin{array}{l}\text { Difference } \\
p\end{array}$} & \multicolumn{5}{|c|}{ Correlations } \\
\hline & & & & & 1 & 2 & 3 & 4 & 5 \\
\hline 1 & Repurchase intent & $6.53(2.11)$ & $6.73(2.12)$ & .000 & & .15 & .65 & .51 & .56 \\
\hline 2 & Relational switching costs & $3.32(2.53)$ & $3.40(2.45)$ & .003 & .10 & & .12 & .09 & .08 \\
\hline 3 & Public brand image & $6.69(1.70)$ & $6.93(1.67)$ & .000 & .71 & .07 & & .58 & .64 \\
\hline 4 & Perceived value & $6.43(1.78)$ & $6.56(1.72)$ & .000 & .53 & .06 & .63 & & .63 \\
\hline 5 & Customer satisfaction & $6.70(1.70)$ & $6.81(1.70)$ & .000 & .60 & .05 & .67 & .65 & \\
\hline
\end{tabular}

For all correlations (men above diagonal, women below diagonal), $p<.05$

$S D$ standard deviation. Sample size: 30,500 (men: 15,685; women: 14,815) 
Paz in Bolivia; and Salt Lake City-Ogden (Utah) in the U.S. Consequently, our sample represents urban consumers. Our data collection systematically targeted a balanced mix of locations such as public places, malls, universities, managerial conferences, firms, and public institutions, which would maximize the sample representativeness under budget restrictions. We distributed the questionnaires personally to consumers willing to participate in our study. Some respondents sent us the questionnaires by mail. All of them received a small present as an incentive. As we did not observe any gender bias among the consumers evading our personal approaches, the repercussions of this potential non-response bias on our analysis of gender differences may be limited. Using Armstrong and Overton's (1977) method, we tested for nonresponse bias by comparing early (first $25 \%$ : immediate responses) and late respondents (last 25\%: late mail respondents, closest to non-respondents according to Armstrong and Overton) in each country with respect to gender and the constructs under investigation. There were no significant differences.

From our dataset, we removed all industry-specific sets of responses with missing data and with identical answers to all questions where we unanimously deemed this to be a consequence of respondent fatigue. Table 1 gives an overview of the sample distribution. Our final dataset consists of 3,838 valid questionnaires and 30,500 industry-specific sets of responses. The dataset contains a similar number of responses from men and women, overstates the number of consumers in their 20's, and understates the number of senior citizens. Separately for men and women, Table 2 presents descriptive statistics and the correlation matrix for the pooled dataset of all industries and countries.

Common method variance (CMV) can weaken the conclusions drawn from cross-sectional research. Following Lindell and Whitney's (2001) procedure to reduce and examine CMV, we varied our scale anchors and added a question conceptually unrelated with the other variables: proneness to stress (Hofstede and Hofstede 2005). Based on the pooled dataset of all countries and industries, we calculated the correlations between this and the other variables of Table 2. All correlations are negative ( -.002 to -.072$)$. According to Lindell and Whitney (2001), the smallest positive correlation is an upper bound on CMV, and the existence of a negative correlation indicates the absence of CMV. Hence, the negative correlations indicate that our study does not seem to suffer from CMV.

\section{Results}

In order to test our hypotheses that include moderating effects of country (H2-H3) and industry differences (H4-H5), we used hierarchical linear modeling (HLM) of the full dataset pooled across countries and industries (Kreft and de Leeuw 1998). Our cross-classified HLM models consist of two hierarchical dimensions. Along the spatial dimension, responses for up to ten industries per respondent (level 1) are nested within respondents (level 2) who are nested within countries (level 3). Along the industry dimension, industry-specific responses (level 1) are nested within industries (level 2).

To test our hypotheses, we used an HLM model with repurchase intent as the dependent variable and the following independent variables: an intercept; age as a control variable; relational switching costs (H1-H5: a), public brand image (H1H5: b), perceived value (H1-H5: c), and customer satisfaction (H1-H5: d) as provider-related customer attitudes; a gender dummy variable (1: female; -1 : male) and its two-way interactions with the provider-related customer attitudes (H1a-d); the country-specific level of gender egalitarianism practices (House et al. 2004), its two-way interactions with the provider-related customer attitudes (H3a-d), and their three-way interactions with gender (H2a-d); and an industry dummy variable (1: services; -1: products), its two-way interactions with the provider-related customer attitudes, and their three-way interactions with gender ( $\mathrm{H} 4 \mathrm{a}-\mathrm{d})$ as well as gender egalitarianism (H5a-d). All continuous variables were mean-centered before calculating interactions. As we theorized that all hypotheses involving effects of public brand image and perceived value on repurchase intent might analogously hold regarding their effects on customer satisfaction, we used an additional HLM model with customer satisfaction as the dependent variable. In line with our conceptual model (see Fig. 1), it contains the same independent variables excluding relational switching costs and customer satisfaction. Both HLM models include four levelspecific error terms (industry-specific response, respondent, country, industry) and random terms capturing the variation of level 1 effects across all higher levels.

Table 3 presents the results of our HLM analyses for the full models (model 1) and for optimized models (model 2) omitting all non-marginally significant effects unless a higher-order interaction term involving this effect is at least marginally significant. Here, marginal significance refers to a two-sided $p<.1$ and a one-sided $p<.05$, which statisticians consider appropriate for testing one-sided (all except H1a and H3a) hypotheses (Kreft and de Leeuw 1998). Keeping non-significant lower-order terms is necessary when interpreting higher-order terms as moderating effects (Kreft and de Leeuw 1998). For instance, the effect of (services $\times$ customer satisfaction) on repurchase intent is not omitted because the effect of (services $\times$ gender egalitarianism $\times$ customer satisfaction) is at least marginally significant. Our interpretations will refer to the optimized models (model 2), which involve less multi-collinearity among interaction effects and are more parsimonious (Kreft and de Leeuw 1998).

Our analyses explain $58 \% / 57 \%$ of the variance in repurchase intent/customer satisfaction, which compares well to other cross-industry models (Fornell et al. 2005; Johnson et al. 2001). In terms of provider-related customer attitudes, customer satisfaction is most strongly driven (according to $b$ and $\beta$ : all $p<.001)$ by public brand image $(b=.395)$, followed by 
Table 3 Main and moderating effects of gender and gender egalitarianism on the formation of customer satisfaction and repurchase intent (HLM)

\begin{tabular}{|c|c|c|c|c|c|}
\hline \multirow[t]{3}{*}{ Independent variable } & \multicolumn{4}{|c|}{ Dependent variable } & \multirow[t]{3}{*}{ Hypothesis } \\
\hline & \multicolumn{2}{|c|}{ Customer satisfaction } & \multicolumn{2}{|c|}{ Repurchase intent } & \\
\hline & Model 1 & Model 2 & Model 1 & Model 2 & \\
\hline \multicolumn{6}{|l|}{ Control variables } \\
\hline Intercept & $109.17 * * *$ & $108.61 * * *$ & $56.95 * * *$ & $56.89^{* * *}$ & \\
\hline Age & .35 & .35 & -.67 & -.67 & \\
\hline \multicolumn{6}{|l|}{ Provider-related customer attitudes } \\
\hline Relational switching costs & & & $16.20 * * *$ & $16.19 * * *$ & \\
\hline Public brand image & $75.63 * * *$ & $75.91 * * *$ & $86.63 * * *$ & $87.11^{* * *}$ & \\
\hline Perceived value & $70.18 * * *$ & $70.92 * * *$ & $19.37 * * *$ & $19.59^{* * *}$ & \\
\hline Customer satisfaction & & & $35.74 * * *$ & $35.79 * * *$ & \\
\hline \multicolumn{6}{|l|}{ Gender differences } \\
\hline Female $(1$, vs. male: -1$)$ & -1.50 & -1.11 & -1.39 & -1.42 & \\
\hline Female $\times$ Relational switching costs & & & $-2.96^{* *}$ & $-2.94 * *$ & H1a: $-/+$ \\
\hline Female $\times$ Public brand image & $2.92 * *$ & $2.75^{* *}$ & $6.48 * * *$ & $6.51 * * *$ & H1b: + \\
\hline Female $\times$ Perceived value & -.91 & & -1.39 & $-1.99 *$ & H1c: - \\
\hline Female $\times$ Customer satisfaction & & & -1.08 & & H1d: - \\
\hline \multicolumn{6}{|l|}{ Gender-related country differences } \\
\hline Gender egalitarianism $[\mathrm{GE}]$ & $3.12 *$ & $3.14^{*}$ & 1.12 & 1.13 & \\
\hline GE $\times$ Relational switching costs & & & $-5.57 * * *$ & $-5.57 * * *$ & H3a: $-/+$ \\
\hline GE $\times$ Public brand image & $9.81 * * *$ & $9.78 * * *$ & $6.21 * * *$ & $6.17 * * *$ & H3b: + \\
\hline GE $\times$ Perceived value & $-8.10 * * *$ & $-8.13 * * *$ & $-2.51^{*}$ & $-2.88 * *$ & H3c: - \\
\hline $\mathrm{GE} \times$ Customer satisfaction & & & $-2.96^{* *}$ & $-2.95 * *$ & H3d: - \\
\hline \multicolumn{6}{|l|}{ Moderating effects of country differences on gender differences } \\
\hline GE $\times$ Female & .00 & & -.97 & & \\
\hline GE $\times$ Female $\times$ Relational switching costs & & & -.32 & & H2a: +/- \\
\hline GE $\times$ Female $\times$ Public brand image & 1.42 & & -.83 & & $\mathrm{H} 2 \mathrm{~b}:-$ \\
\hline GE $\times$ Female $\times$ Perceived value & .52 & & .64 & & $\mathrm{H} 2 \mathrm{c}:+$ \\
\hline GE $\times$ Female $\times$ Customer satisfaction & & & .53 & & H2d: + \\
\hline \multicolumn{6}{|l|}{ Industry differences } \\
\hline Services (1, vs. products: -1$)$ & -1.72 & -1.74 & $5.54 * * *$ & $5.51 * * *$ & \\
\hline Services $\times$ Relational switching costs & & & $-9.96^{* * *}$ & $-9.88^{* * *}$ & \\
\hline Services $\times$ Public brand image & $9.45^{* * *}$ & $9.53 * * *$ & $-8.44 * * *$ & $-8.48 * * *$ & \\
\hline Services $\times$ Perceived value & $-2.25^{*}$ & $-2.20^{*}$ & $2.13^{*}$ & $1.97^{*}$ & \\
\hline Services $\times$ Customer satisfaction & & & .98 & 1.06 & \\
\hline \multicolumn{6}{|l|}{ Moderating effects of industry differences on gender differences } \\
\hline Services $\times$ Female & .17 & & $2.04 \dagger$ & $2.10 \dagger$ & \\
\hline Services $\times$ Female $\times$ Relational switching costs & & & $1.66 \dagger$ & $1.67 \dagger$ & H4a: + \\
\hline Services $\times$ Female $\times$ Public brand image & -.44 & & $1.79 \dagger$ & $1.87 \dagger$ & H4b: + \\
\hline Services $\times$ Female $\times$ Perceived value & -.86 & & $-1.69 \dagger$ & $-2.03 *$ & H4c: - \\
\hline Services $\times$ Female $\times$ Customer satisfaction & & & -.22 & & H4d: + \\
\hline \multicolumn{6}{|c|}{ Moderating effects of industry differences on country differences } \\
\hline Services $\times$ GE & $-2.12 *$ & $-2.08^{*}$ & -1.32 & -1.55 & \\
\hline Services $\times$ GE $\times$ Relational switching costs & & & $2.55^{*}$ & $2.34^{*}$ & H5a: + \\
\hline Services $\times$ GE $\times$ Public brand image & $1.99^{*}$ & $2.00^{*}$ & -1.55 & & $\mathrm{H} 5 \mathrm{~b}:+$ \\
\hline Services $\times$ GE $\times$ Perceived value & $-1.70 \dagger$ & $-1.71 \dagger$ & -1.30 & & H5c: - \\
\hline Services $\times \mathrm{GE} \times$ Customer satisfaction & & & $3.81 * * *$ & $2.83 * *$ & H5d: + \\
\hline HLM Pseudo R² (measure by Kreft and de Leeuw 1998) & .57 & .57 & .58 & .58 & \\
\hline
\end{tabular}

t-values shown. Sample size: 30,500 industry-specific evaluations, 3,838 consumers, 10 industries, and 5 countries Error terms: level 1/respondent/country/industry intercepts, variation of level 1 coefficients across countries $\dagger p<.1 ; * p<.05 ; * * p<.01 ; * * * p<.001$ (2-tailed) 
perceived value $(b=.356)$. Repurchase intent is most strongly influenced by public brand image $(b=.608)$, followed by customer satisfaction $(b=.252)$, perceived value $(b=.131)$, and relational switching costs $(b=.062$; all $p<.001)$. When accounting for indirect effects mediated by customer satisfaction (see Fig. 1), perceived value $(b=.221)$ and public brand image $(b=.707)$ have higher overall influence than direct effects on repurchase intent.

Concerning our core hypotheses (H1a-d), the results for two-way interactions of gender confirm that the effect of public brand image on repurchase intent is stronger $(\mathrm{H} 1 \mathrm{~b}$ supported) and the effects of relational switching costs (H1a supported as dominant vis-à-vis H1a [alt]) and perceived value (H1c supported) are weaker for women than men. An analogous gender difference exists in the effect of public brand image, but not in the effect of perceived value, on customer satisfaction. Hence, the gender difference in the direct effect of public brand image on repurchase intent (H1b) is amplified by an analogous gender difference in its indirect effect mediated by customer satisfaction. Unlike in the exploratory analysis by Mittal and Kamakura (2001), our analyses did not detect any gender difference in the effect of customer satisfaction on repurchase intent (H1d not supported).

Furthermore, we hypothesized that the country-specific degree of gender egalitarianism exerts the same moderating effects (H3a-d) as female (vs. male) gender (H1a-d) on the formation of repurchase intent. Our results confirm these hypotheses and even show analogous indirect effects mediated by customer satisfaction. Specifically, the effect of public brand image on repurchase intent is stronger $(\mathrm{H} 3 \mathrm{~b}$ supported) and the effects of relational switching costs (H3a supported as dominant vis-à-vis $\mathrm{H} 3 \mathrm{a}$ [alt], analogous to the results for H1a), perceived value (H3c supported), and customer satisfaction (H3d supported) are weaker in countries with stronger gender egalitarianism. Moreover, the moderating effects of gender egalitarianism on the influences of public brand image (H3b) and perceived value $(\mathrm{H} 3 \mathrm{c})$ on repurchase intent are amplified by analogous effects
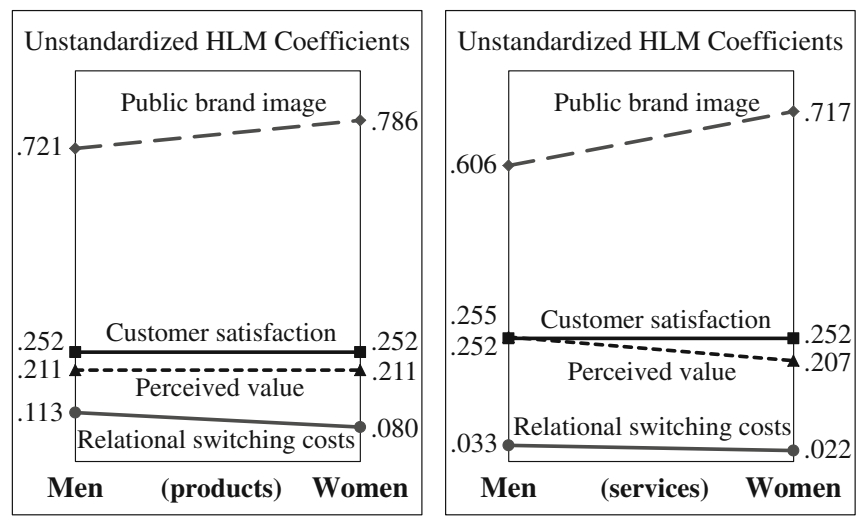

mediated by customer satisfaction. Our results for threeway interactions do not support our hypotheses (H2a-d) that gender egalitarianism weakens the gender differences in the formation of repurchase intent (H1a-d).

Regarding industry differences, our results show that services offer more grounds than products for positive moderating effects of female (vs. male) gender (H4a only marginally significant) and gender egalitarianism (H5a supported) on the influence of relational switching costs on repurchase intent. That is, H1a [alt] and H3a [alt] are relatively more justified vis-à-vis $\mathrm{H} 1 \mathrm{a}$ and $\mathrm{H} 3 \mathrm{a}$ for services than products. The gender differences in the effects of public brand image ( $\mathrm{H} 4 \mathrm{~b}$ marginally significant) and perceived value ( $\mathrm{H} 4 \mathrm{c}$ supported) on repurchase intent are stronger for services than products. As our results do not show any moderating effect of gender on the influence of customer satisfaction on repurchase intent (H1d) in the first place, this non-existing effect also does not differ between products and services (H4d). Furthermore, the moderating effect of gender egalitarianism on the influence of customer satisfaction on repurchase intent $(\mathrm{H} 3 \mathrm{~d})$ is stronger for products than services (H5d supported). Its moderating effects on the influences of public brand image and perceived value $(\mathrm{H} 3 \mathrm{~b}-\mathrm{c})$ are stronger for services than products $(\mathrm{H} 5 \mathrm{~b}$ supported, H5c marginally significant), but these industry differences only occur in the formation of customer satisfaction which mediates effects on repurchase intent.

Based on at least marginally significant coefficients (twosided $p<.1$ ) from the optimized models in Table 3, Fig. 3 separately portrays these results for men vs. women, low vs. high gender egalitarianism (two-way interactions), and their differences between products and services (three-way interactions). It presents HLM coefficients of overall effects on repurchase intent (i.e., direct effects + effects mediated by customer satisfaction). The values for low and high gender egalitarianism each differ from the mean by one standard deviation (.37) of the GLOBE survey (House et al. 2004).

Analyses with subsets of our data show that our HLM model explains $52 / 60 \%\left(\mathrm{R}^{2}\right)$ of the variance in repurchase intent for
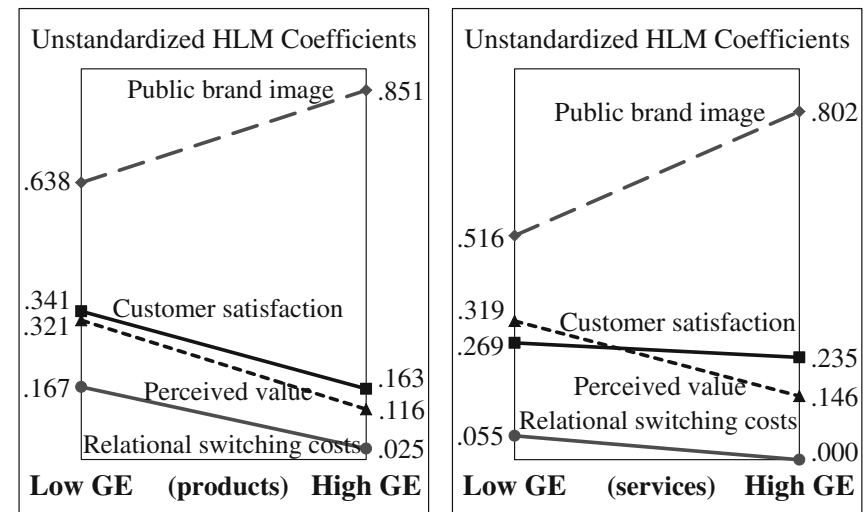

Fig. 3 Determinants of repurchase intent and their effect sizes: men vs. women and low vs. high gender egalitarianism. Notes: Overall (direct + mediated) effects calculated based on the optimized models in Table 3. GE Gender egalitarianism 
men and $56 / 67 \%$ for women in the case of products/services. Country-specific analyses explain $50 \%$ (Thailand) to $67 \%$ (U.S.) and industry-specific analyses explain $43 \%$ (mobile phone) to $67 \%$ (bank) of the variance in repurchase intent. In line with our results for H2a-d, Japan as a country with low gender egalitarianism exhibits the largest (by a slight margin) gender difference only in the effect of relational switching costs, but not in the other effects. Hence, our large Japanese sample does not artificially inflate the gender differences detected by our study. In several but not all industries, our survey also included an industry-specific question on consumer experience. For these industries, we ran additional analyses including moderating effects of experience on the formation of repurchase intent to verify whether the influence of experience might alter our conclusions, which is not the case.

While past research has not developed and tested theory on moderating effects of gender on the formation of repurchase intent, a single study developed theory on a main effect of gender on customer loyalty. Melnyk et al. (2009, Studies 4-5) predicted and found that intentions to repurchase from firms are higher for men than women. Our results in Table 3 do not confirm this prediction.

\section{Discussion}

General discussion, limitations, and directions for future research

Knowledge of gender differences in the success factors driving repurchase intent would enable managers to separately optimize repurchase intent for male and female customers and thus reach a higher overall level of customer repurchase intent. Drawing on the gender psychology and marketing literature (Burnham et al. 2003; Johnson et al. 2001), we thus developed hypotheses about gender differences in the effects of relational switching costs (H1a vs. H1a [alt]), public brand image (H1b), perceived value (H1c), and customer satisfaction (H1d) on repurchase intent. Further hypotheses focused on the moderating effects of country differences in gender egalitarianism (H2a to $\mathrm{H} 3 \mathrm{~d})$ and of contextual differences between products and services ( $\mathrm{H} 4 \mathrm{a}$ to $\mathrm{H} 5 \mathrm{~d}$ ). Using hierarchical linear modeling, we tested these hypotheses with consumer data from five countries and ten industries.

Our empirical results confirm that public brand image has a stronger influence (H1b) and perceived value (quality compared to the price) has a weaker influence $(\mathrm{H} 1 \mathrm{c})$ on repurchase intent for women than for men. As Fig. 3 illustrates, the moderating effect of gender on the effect of public brand image is particularly pronounced. Both effects appear to be stronger for services than products $(\mathrm{H} 4 \mathrm{c}$; $\mathrm{H} 4 \mathrm{~b}$ only marginally significant). Therefore, gender-based market segmentation in terms of public brand image and perceived value seems to be more crucial in service-oriented than product-oriented industries. Our analyses could not replicate the finding of significant gender differences in the importance of customer satisfaction (H1d) in the exploratory analysis by Mittal and Kamakura (2001), even though we examined each country and industry included in our dataset. Potentially, this gender difference is limited to certain contexts which future research may seek to identify.

Based on a modern theory of gender (Baumeister and Sommer 1997; Melnyk et al. 2009), we further developed two opposing hypotheses about whether the higher collectively interdependent self-construal (i.e., focus on collective relationships) of men (H1a) or the higher relationally interdependent self-construal (i.e., focus on individual relationships) of women (H1a [alt]) leads to stronger effects of relational switching costs on repurchase intent. Our results indicate that the mechanism predicted by H1a is dominant across industries, whereas the mechanism predicted by H1a [alt] may be partially relevant to services (H4a marginally significant). The growth of companies over the past decades and the transformation of their customer groups into less personal, more anonymous brand communities (Muñiz and O'Guinn 2001) thus may have led to a dominance of collective over individual relationships in governing customer behavior, especially in product industries. Without distinguishing between individual and collective relationships, traditional gender theory emphasizes that women are more relationally interdependent than men in general, whereas men are more relationally independent (Cataldi and Reardon 1996; Cross and Madson 1997; Rubin and Brown 1975). This theoretical backdrop would imply that women generally react more strongly than men to relational switching costs. However, this prediction is contrary to our finding of a greater influence of relational switching costs for men than women. Hence, gender differences in the role of relational switching costs in customer decision making are more accurately described by the modern and somewhat non-intuitive gender theory of Baumeister and Sommer (1997) and Melnyk et al. (2009) than by traditional gender theory (Cataldi and Reardon 1996; Cross and Madson 1997; Rubin and Brown 1975).

Furthermore, our results indicate that the gender differences in the formation of repurchase intent (H1a-d) are not significantly weaker in national cultures with a higher degree of gender egalitarianism and thus smaller gender role differences (H2a-d). As gender egalitarianism also refers to the degree to which innate female (vs. male) values are desirable for the society as a whole (Hofstede and Hofstede 2005; House et al. 2004), we also hypothesized that gender egalitarianism exerts the same moderating effects as female (vs. male) gender on the formation of repurchase intent (H3a-d) with the same differences between products and services (H5a-d). These results were supported, but some differences between products and services ( $\mathrm{H} 5 \mathrm{~b} ; \mathrm{H} 5 \mathrm{c}$ marginally significant) seem to apply only to the formation of customer 
satisfaction, which mediates effects on repurchase intent. In summary, our results imply that innate gender differences (H1a-d) and cultural gender role differences (H3a-d) independently influence the formation of customer satisfaction and repurchase intent in analogous ways, whereas gender role differences do not amplify innate gender differences through interactions (H2a-d). We encourage future research to investigate whether this principle also extends to other types of consumer behavior and thus to address the dearth of consumer research on the role of gender egalitarianism.

As a secondary contribution, we used our broad dataset to empirically examine the only established theory on a main effect of gender on customer loyalty. Similar to other studies using gender as a control variable (Bell et al. 2005; BendallLyon and Powers 2002; Dimitriades 2006; Kim and Yoon 2004; McGoldrick and Andre 1997; Mittal and Kamakura 2001), our results do not confirm that intentions to repurchase from firms are higher for men than women (Melnyk et al. 2009, Studies 4-5). Our research suggests that higher collective interdependence among men than women, which Melnyk et al. (2009, Studies 4-5) presume to translate into higher intentions to repurchase from firms, might rather translate into a greater influence of relational switching costs on repurchase intent (H1a). While this mechanism may indeed lead to higher repurchase intent eventually, such an outcome also depends on context-specific (e.g., H4) gender differences in the effects of other variables influencing repurchase intent. We encourage future research to take an even closer look at these mechanisms.

A limitation of our research is that a higher-level sample size of merely ten industries and five countries is probably not sufficient to identify all contextual conditions moderating the focal effects across industries and countries (Kreft and de Leeuw 1998). We invite future research to examine more countries and industries, with the added reason that academic marketing research generally suffers from an overgeneralization of industryand country-specific findings. Moreover, our sample overstates the number of young consumers and understates the number of senior citizens in the population. While the consequences of this bias may be limited as analyses across age groups showed consistent results, future research could revalidate our results for senior citizens. Senior citizens have usually grown up with more pronounced gender roles, but retirement and long-time partnerships may have caused higher similarity and smaller value differences among partners. Furthermore, future research may retest our hypotheses with objective repurchase data rather than data on repurchase intent, although the cost of such data would certainly limit the scope of analysis.

Our statistical models have greater explanatory power in the U.S. $\left(\mathrm{R}^{2}: 67 \%\right)$ than other countries (minimum: $50 \%$ in Thailand). As our theory mainly drew on the U.S. literature, this is not surprising and defines a need for more international research on repurchase intent. Since few $R^{2}$ values in comparable studies exceed ours, not all drivers of repurchase intent seem to have been identified by the literature. Of interest to future research, our results show a higher $\mathrm{R}^{2}$ for women than men. This may indicate that men are more responsive to determinants of repurchase intent which the literature has not yet identified.

Scholars may also extend our research approach to the literature on gender differences in complaint behavior and in the determinants of service recovery, where some studies confirmed (McColl-Kennedy et al. 2003; Murad et al. 2009) and others rejected (Garrett et al. 1997; Ndubisi and Ling 2007) the idea of significant gender differences. Since most of these studies are limited to contexts involving a single country and industry, this stream of literature might benefit from a broad investigation of contextual influences (in analogy to H2-H5) to resolve contradictions among the results of different studies.

\section{Managerial implications}

High levels of repurchase intent among customers contribute substantially to long-term profitability, especially in saturated markets (Fornell et al. 2005). According to Reichheld and Sasser (1990), reducing customer churn by $5 \%$ boosts profits by $25 \%$ to $85 \%$. Our results indicate that public brand image has the strongest direct impact on repurchase intent, followed by customer satisfaction, perceived value, and relational switching costs. A favorable public brand image derives from social contributions, reliability, professionalism, and innovativeness as well as from communicating these virtues through advertising (Ball et al. 2006; Türkyılmaz and Özkan 2007). Hence, advertising and social contributions may be more important and personal customer relationships may be less important on average than suggested by past, context-specific marketing studies (e.g., Burnham et al. 2003).

Managers frequently use gender as a criterion for market segmentation because it meets several of the requirements for successful implementation: easy to identify, easy to access, and large enough to be profitable (Putrevu 2001). As marketing resources are not unlimited, managers need to make tradeoffs when they seek to increase the level of repurchase intent among customers. An efficient investment policy would allocate strategic marketing investments in line with the relative importance of different determinants of repurchase intent. As our research indicates that this relative importance differs by gender, firms would benefit from gender-specific marketing strategies when spending their limited resources. We advise managers to study our results for products and services (see Fig. 3) in order to learn about gender differences in repurchase decision making.

Generally speaking, these results indicate that female customers give public brand image higher weight in repurchase decisions than male customers do. While this gender difference persists across industries, it is particularly pronounced in 
service industries. Hence, investments in advertising and social contributions to boost public brand image (Ball et al. 2006; Türkyılmaz and Özkan 2007) seem to be more effective in retaining female than male customers. Our results further indicate that women focus less on perceived value (i.e., quality compared to the price) than men do. This tendency is especially pronounced in service industries with frequent staff contact, where women may thus be ready to accept higher prices. Contrary to common perceptions, relational switching costs do not contribute to higher customer retention among women than men. Our results even indicate the opposite. Hence, establishing personal relationships might not be as effective in retaining female customers as previously assumed by the marketing literature (Melnyk et al. 2009). Investments in personal relationships thus should aim at charging female customers higher prices rather than at preventing female switching behavior. Since our results are stable across countries, global firms should be able to apply such gender-specific discrimination strategies uniformly across countries.

Our results are important not just to firms seeking to implement a policy of gender-specific market discrimination among their current customers. They are also of crucial importance to firms that currently serve a predominantly male or female customer base and seek to extend their product lines to the opposite sex to capture new markets. In that case, it is necessary to not just develop new products, services, and marketing slogans but also adjust key strategic marketing priorities in line with our results.

Furthermore, our research has important implications for international marketing strategy. In countries with a higher degree of gender egalitarianism (i.e., men and women have more similar gender roles), relational switching costs, perceived value (i.e., quality compared to the price), and customer satisfaction appear to be less effective in securing loyal customers, whereas public brand image appears to be more effective. Of interest to firms with limited resources and a consequential need for strategic trade-offs, these findings imply that advertising and social contributions are more effective, whereas personal customer relationships, quality, and price are less effective when serving national markets with higher gender egalitarianism. The opposite applies to countries with lower gender egalitarianism (e.g., Japan: House et al. 2004). Although these recommendations are valid across industries, their relative strategic importance differs across industries. Specifically, the country differences in the effects of relational switching costs and customer satisfaction on repurchase intent appear to be larger in product industries, whereas the country differences in the effects of public brand image and perceived value on customer satisfaction appear to be larger in service industries. Of course, countries also differ on other cultural dimensions which influence these success factors and thus need to be taken into account (Soares et al. 2007). In order to implement such international market discrimination strategies, information on country differences in gender egalitarianism can be obtained from the well-known GLOBE framework of cultural differences (House et al. 2004).

Acknowledgments We would like to express our gratitude to the anonymous reviewers and the editor, G. Tomas M. Hult, for their valuable comments on previous versions of our manuscript. Moreover, we would like to thank Gulmire Ablat, Tanyanuparb Anantana, Zhuo Chen, Boris Herbas Torrico, and all survey participants for their contribution to the data collection.

Open Access This article is distributed under the terms of the Creative Commons Attribution License which permits any use, distribution, and reproduction in any medium, provided the original author(s) and the source are credited.

\section{References}

Aaker, D. A. (1991). Managing brand equity. New York: Free Press.

Armstrong, J. S., \& Overton, T. S. (1977). Estimating nonresponse bias in mail surveys. Journal of Marketing Research, 14(3), 396-402.

Ball, D., Coelho, P. S., \& Machás, A. (2004). The role of communication and trust in explaining customer loyalty: an extension to the ECSI model. European Journal of Marketing, 38(9), 1272-1293.

Ball, D., Coelho, P. S., \& Vilares, M. J. (2006). Service personalization and loyalty. Journal of Services Marketing, 20(6), 391-403.

Baumeister, R., \& Leary, M. R. (1995). The need to belong: desire for interpersonal attachments as a fundamental human motivation. Psychological Bulletin, 117(3), 497-529.

Baumeister, R., \& Sommer, K. L. (1997). What do men want? Gender differences and two spheres of belongingness: comment on Cross \& Madson. Psychological Bulletin, 122(1), 38-44.

Bell, S. J., Auh, S., \& Smalley, K. (2005). Customer relationship dynamics: service quality and customer loyalty in the context of varying levels of customer expertise and switching costs. Journal of the Academy of Marketing Science, 33(2), 169-183.

Bendall-Lyon, D., \& Powers, T. L. (2002). The impact of gender differences on change in satisfaction over time. Journal of Consumer Marketing, 19(1), 12-23.

Bergkvist, L., \& Rossiter, J. R. (2007). The predictive validity of multiitem versus single-item measures of the same constructs. Journal of Marketing Research, 44(2), 175-184.

Burnham, T. A., Frels, J. K., \& Mahajan, V. (2003). Consumer switching costs: a typology, antecedents, and consequences. Journal of the Academy of Marketing Science, 31(2), 109-126.

Campbell, C. (1997). Shopping, pleasure, and the sex war. In P. Falk \& C. Campbell (Eds.), The shopping experience? (pp. 166-176). London: Sage Publications.

Carleton, R. N., Collimore, K. C., \& Asmundson, G. J. G. (2007). Social anxiety and fear of negative evaluation: construct validity of the BFNE-II. Journal of Anxiety Disorders, 21(1), 131-141.

Cataldi, A. E., \& Reardon, R. (1996). Gender, interpersonal orientation, and manipulation tactic use in close relationships. Sex Roles, 35(3/4), 205-218.

Chiu, H.-C. (2002). A study on the cognitive and affective components of service quality. Total Quality Management and Business Excellence, 13(2), 265-274.

Cron, W. L., Gilly, M. C., Graham, J. L., \& Slocum, J. W. (2009). Gender differences in the pricing of professional services: implications for income and customer relationships. Organizational Behavior and Human Decision Processes, 109(1), 93-105. 
Cross, S. E., \& Madson, L. (1997). Models of the self: self-construals and gender. Psychological Bulletin, 122(1), 5-37.

Dimitriades, Z. S. (2006). Customer satisfaction, loyalty and commitment in service organizations: some evidence from Greece. Management Research News, 29(12), 782-800.

Eagly, A. H. (1987). Sex differences in social behavior: A social-role interpretation. Hillsdale: Lawrence Erlbaum Associates.

Eagly, A. H., \& Carli, L. L. (1981). Sex of researchers and sextyped communications as determinants of sex differences on influenceability: a meta-analysis of social influence studies. Psychological Bulletin, 90(1), 1-20.

Escalas, J. E., \& Bettman, J. R. (2005). Self-construal, reference groups, and brand meaning. Journal of Consumer Research, 32(3), 378-389.

Fischer, M., Völckner, F., \& Sattler, H. (2010). How important are brands? A cross-category, cross-country study. Journal of Marketing Research, 47(5), 823-829.

Fornell, C., VanAmburg, D., Morgeson, F., Anderson, E. W., Bryant, B. E., \& Johnson, M. D. (2005). The American customer satisfaction index at ten years. Ann Arbor: University of Michigan.

Garbarino, E., \& Strahilevitz, M. (2004). Gender differences in the perceived risk of buying online and the effects of receiving a site recommendation. Journal of Business Research, 57(7), 768-775.

Garrett, D. E., Meyers, R. A., \& West, L. (1997). Sex differences and consumer complaints: Do men and women communicate differently when they complain to customer service representatives? Journal of Consumer Satisfaction, Dissatisfaction, and Complaining Behavior, 10, 116-130.

Gelfand, M. J., Smith Major, V., Raver, J. L., Nishii, L. H., \& O'Brien, K. (2006). Negotiating relationally: the dynamics of the relational self in negotiations. Academy of Management Review, 31(2), 427-451.

Habke, A. M., Hewitt, P. L., Norton, G. N., \& Asmundson, G. (1997). The social phobia and social interaction anxiety scales: an exploration of the dimensions of social anxiety and sex differences in structure and relations with pathology. Journal of Psychopathology and Behavioral Assessment, 19(1), 21-39.

Hofstede, G., \& Hofstede, G. J. (2005). Cultures and organizations: Software of the mind (2nd ed.). New York: McGraw-Hill.

Homburg, C., Kuester, S., \& Krohmer, H. (2009). Marketing management: A contemporary perspective. London: McGraw-Hill.

House, R. J., Hanges, P. J., Javidan, M., Dorfman, P. W., \& Gupta, V. (2004). Culture, leadership, and organizations. Thousand Oaks: Sage Publications.

Iacobucci, D., \& Ostrom, A. (1993). Gender differences in the impact of core and relational aspects of services on the evaluation of service encounters. Journal of Consumer Psychology, 2(3), 257-286.

Johnson, M. D., Gustafsson, A., Andreassen, T. W., Lervik, L., \& Cha, J. (2001). The evolution and future of national customer satisfaction index models. Journal of Economic Psychology, 22(2), 217-245.

Kim, H.-S., \& Yoon, C.-H. (2004). Determinants of subscriber churn and customer loyalty in the Korean mobile telephony market. Telecommunications Policy, 28(9-10), 751-765.

Kreft, I., \& de Leeuw, J. (1998). Introducing multilevel modeling. London: Sage Publications.

Lawrence, J. W., Fauerbach, J. A., \& Thombs, B. D. (2006). A test of the moderating effect of importance of appearance in the relationship between perceived scar severity and body-esteem among adult burn survivors. Body Image, 3(2), 101-111.

Lindell, M. K., \& Whitney, D. J. (2001). Accounting for common method variance in cross-sectional research designs. Journal of Applied Psychology, 86(1), 114-121.

McColl-Kennedy, J. R., Daus, C. S., \& Sparks, B. A. (2003). The role of gender in reactions to service failure and recovery. Journal of Service Research, 6(1), 66-82.

McGoldrick, P. J., \& Andre, E. (1997). Consumer misbehaviour: promiscuity or loyalty in grocery shopping. Journal of Retailing and Consumer Services, 4(2), 73-81.
Melnyk, V., van Osselaer, S. M. J., \& Bijmolt, T. H. A. (2009). Are women more loyal customers than men? Gender differences in loyalty to firms and individual service providers. Journal of Marketing, 73(4), 82-96.

Meyers-Levy, J. (1988). The influence of sex roles on judgment. Journal of Consumer Research, 14(4), 522-530.

Mittal, V., \& Kamakura, W. A. (2001). Satisfaction, repurchase intent, and repurchase behavior: investigating the moderating effect of customer characteristics. Journal of Marketing Research, 38(1), 131-142.

Moutinho, L., Davies, F., \& Curry, B. (1996). The impact of gender on car buyer satisfaction and loyalty. Journal of Consumer Services and Retailing, 3(3), 135-144.

Muñiz, A. M., Jr., \& O'Guinn, T. C. (2001). Brand community. Journal of Consumer Research, 27(4), 412-432.

Murad, M. H., Gjerde, C. L., Bobula, J., Ostrov, M., \& Murad, M. S. (2009). Gender and patient complaints: are they related? Quality in Primary Care, 17(5), 351-357.

Ndubisi, N. O. (2006). Effect of gender on customer loyalty: a relationship marketing approach. Marketing Intelligence and Planning, 24(1), 48-61.

Ndubisi, N. O., \& Ling, T. Y. A. (2007). Evaluating gender differences in the complaint behavior of Malaysian consumers. Asian Academy of Management Journal, 12(2), 1-13.

Ngobo, P. V. (2004). Drivers of customers' cross-buying intentions. European Journal of Marketing, 38(9/10), 1129-1157.

Noble, S. M., Griffith, D. A., \& Adjei, M. T. (2006). Drivers of local merchant loyalty: understanding the influence of gender and shopping motives. Journal of Retailing, 82(3), 177-188.

Otnes, C., \& McGrath, M. A. (2001). Perceptions and realities of male shopping behavior. Journal of Retailing, 77(1), 111-137.

Putrevu, S. (2001). Exploring the origins and information processing differences between men and women: implications for advertisers. Academy of Marketing Science Review, 10, 1-15.

Reichheld, F. F., \& Sasser, W. E. (1990). Zero defections: quality comes to services. Harvard Business Review, 68(5), 105-111.

Rubin, J. Z., \& Brown, B. R. (1975). The social psychology of bargaining and negotiation. San Diego: Harcourt Brace Jovanovich.

Schwartz, S. H., \& Rubel-Lifschitz, T. (2005). Sex differences in value priorities: cross-cultural and multimethod studies. Journal of Personality and Social Psychology, 89(6), 1010-1028.

Schwartz, S. H., \& Rubel-Lifschitz, T. (2009). Cross-national variation in the size of sex differences in values: effects of gender equality. Journal of Personality and Social Psychology, 97(1), 171-185.

Shemwell, D. J., Jr., \& Cronin, J. J., Jr. (1995). Trust and commitment in customer/service-provider relationships: an analysis of differences across service types and between sexes. Journal of Customer Service in Marketing and Management, 1(2), 65-75.

Soares, A. M., Farhangmehr, M., \& Shoham, A. (2007). Hofstede's dimensions of culture in international marketing studies. Journal of Business Research, 60(3), 277-284.

Stuhlmacher, A. F., \& Walters, A. E. (1999). Gender differences in negotiation outcome: a meta-analysis. Personnel Psychology, 52(3), 653-677.

Tian, K. T., Bearden, W. O., \& Hunter, G. L. (2001). Consumers' need for uniqueness: scale development and validation. Journal of Consumer Research, 28(1), 50-66.

Türkyılmaz, A., \& Özkan, C. (2007). Development of a customer satisfaction index model: an application to the Turkish mobile phone sector. Industrial Management \& Data Systems, 107(5), 672-687.

Vázquez-Carrasco, R., \& Foxall, G. R. (2006). Positive vs. negative switching barriers: the influence of service consumers' need for variety. Journal of Consumer Behavior, 5(4), 367-379.

Zelditch, M. (1955). Role differentiation in the nuclear family: A comparative study. In T. Parsons \& R. Bales (Eds.), Family, socialization and interaction process (pp. 307-351). Glencoe: Free Press. 